\title{
ASPIRATION IN NEPALI
}

\author{
Krishna Prasad Chalise
}

This experiment studies the effect of aspiration on PVD, $C D, A C T$ and $S A$ of the Nepali plosives and finds that the voiced aspirates (also called breathy voiced) share the features of both the voiced plosives and aspirated plosives. So, they are voiced aspirates phonetically. To define aspiration in terms of voicing lag is inappropriate because it is found in both the voiceless and voiced plosives in Nepali.

Keywords: frication, voicing lag, preceding vowel, after closure time, breathy voiced, VOT, ACT

\section{Introduction}

Phonologically, Nepali has 16 plosive sounds with four-way contrast in terms of phonation: voiceless vs. voiced and unaspirated vs. aspirated, and four way contrast in the places of articulation: bilabial, dental, retroflex and velar. As in Hindi (Lisker and Abramson 1964, Ohala and Ohala 1972, Benguerel and Bhatia 1980 and Dutta 2007) and Bengali (Mikuteit and Reetz, 2007), whether the voiced aspirates in Nepali are phonetically aspirated plosives or they represent a distinct mode of phonationhas been a matter of debate (Poon and Mateer1985, Pokharel 1989 and Chalise 2017).

In the Sanskrit phonetic literature the voiced aspirates have been identified as the combined articulation of $n \bar{a} d a$ (voicing) and $s v \bar{a} s a$ (aspiration) and clearly described the distinction between the two phonetic features (Dutta 2007:3). In contrast to the Sanskrit phonetic tradition, Ladefoged (1975: 127) regards voiced aspirate to be a distinct mode of phonation. He claims that the voiced aspirates are phonetically distinct sounds because 'they are neither voiced (in the sense of having regular vibrations of the vocal cords) nor aspirated (in the sense of having a period of voicelessness) during and after the release of the closure'. So he uses the terms breathy voice or murmur to refer to the voice aspirates. The idea of Ladefoged has been established as a standard view about the voice aspirates in phonetics.

But there are a number of phoneticians who support the idea that voiced aspirates are the combination of voice and aspiration. As cited in
Dutta (2007:7) 'Lombardi (1994) argues that the voiced aspirates in Hindi and other languages are both voiced and aspirated'. Her argument is based on the findings of Dixit (1989), Yadav (1984), Ingemann and Yadav (1978) and Kagaya and Hirose (1975). Ingemann and Yadav (1978) claim that the concept of Ladefoged (1975) has made the pattern of plosives in four-category languages asymmetrical and counter intuitive; and it has created problems with the historical description of the sounds in question.

But Ladefoged and Johnson (2011) assert the voiced aspirates to be voiced sounds and the term 'breathy voiced' used to refer to the class itself asserts them to be voiced sounds.It shows that there is no controversy regarding the voicing of the voiced aspirates but the controversy is whether they are aspirated or not. So the foundation of the controversy lies on how we define aspiration.

There are some issues to be dealt with while we try to understand what aspiration is. The first issue is whether aspiration is the feature of any class of sounds, only the plosive sounds or only the voiceless plosive sounds. The second issue is whether aspiration is phonetically noise or voicelessness. Similarly, which phase of sound production, onset, hold or release, it belongs to.

Laver (1994: 348) regards aspiration to be the sole property of voiceless plosive. He states that 'aspiration is a feature which can manifest a coordinatory relationship between a voiceless segment and a following voiced at the leading edge of a syllable'. Similarly, a large number of phoneticians regard it to be the property of voiceless plosives and a longer duration of voicelessness or voicing lag (Voice Onset Time) after the release of a plosive indicates an aspirated one and a short voicing lag indicates an unaspirated one (Ladefoged and Johnson 2011:305; Raphel, Borden and Harris 2011:134; Reetz and Jongman 2011:101). From the above literature we understand that aspiration is a release feature of a voiceless plosive. According to this concept, the voiceless unaspirates and aspirates

Nepalese Linguistics, vol. 33 (1), 2018, pp. 16-21 
are characterized by short and long voicing lag respectively which is technically described using the term Voice Onset Time (VOT).

This concept presupposes that voicing lag is found only in the voiceless plosives but in Nepali voicing lag is found in voiced plosives as well and this phenomenon is found in other languages like Bengali (Mikuteit and Reetz, 2007) and Georgian (Vicenik, 2008), too. In Georgian, aspirated stops show longest voicing lag and voiced stops show shortest voicing lag. So voicing lag is found in both voiced and voiceless plosives in the languages. The concept is contradictory because if aspiration is only the feature of the voiceless plosives, voiced plosives should not have voicing lag and if voicing lag is aspiration, it is possible with the voiced plosives, too. So the concept of VOT is contradictory in itself and it does not seem to be logical for the four category languages like Nepali which has already been accepted by Lisker and Abramsom (1964) and Poon and Mateer (1985).

Similarly, aspiration does not seem to be only the feature of plosives as well as their release. In Dzonkha, the national language of Bhutan has contrastive pre-aspirated sonorants as in ləp 'hand' vs. hləp 'more' (Watters 2002:9) which shows that aspiration is a property of a sonorant consonant in the onset position, too.

The VOT model uses the terms 'voicing lag/voicelessness and 'noise' alternatively to refer to aspiration. But voicelessness does not necessarily mean noise because a silence is also a state of voicelessness. So whether aspiration is a type of noise or simply the state of voicelessness is a matter to discuss. Some phoneticians regard aspiration to be a noise produced as a result of glottal and supraglottal friction. Harrington (2010:55) states that 'during the release of a stop the air is pushed out of the vocal tract explosively and this brief period of high airflow may result in aspiration noise'. Similarly, he Harrington (2010:103) further clarifies that 'aspiration is the result of noise source at the glottis that may produce energy below $1 \mathrm{kHz}$.

There are several debates regarding the different aspects of aspiration, so in this experiment, based on the Nepali data, I have tried to find out and compare the acoustic features of the corresponding aspirated and unaspirated plosives, and voiced and voiceless aspirated plosives based on their effects on the preceding vowel, closure time features and release features.

\section{Methodology}

\subsection{Method of data collection}

The words presented in Table 1 consists all the target sounds in [iCi] and [aCa]. Every word was embedded in a carrier sentence as: $\mathrm{X}$, I said $\mathrm{X}$ (where $\mathrm{X}$ is the target word) where the word is uttered as a single word for the first time and a part of the utterance for the second time, and the speakers were asked to utter for three times. Every utterance was followed by a pause so that the speaker could produce each utterance with equal comfort. For the purpose of analysis the word produced as a word was selected. Altogether, there were $[16$ (number of plosives) $\times 2$ (number of environments) $\times 3$ (one word was uttered for three times) $\times 6$ (number of speakers) 576 tokens for analysis.

Table 1: The word list

\begin{tabular}{|c|c|c|c|}
\hline$[\mathrm{k}]$ & {$[\mathrm{t}]$} & {$[\mathrm{t}]$} & [p] \\
\hline [tiki, kaka] & [piti, pata] & {$[$ riti, tata] } & [pipi, papa] \\
\hline$\left[\mathrm{k}^{\mathrm{h}}\right]$ & {$\left[\mathrm{t}^{\mathrm{h}}\right]$} & {$\left[\mathrm{t}^{\mathrm{h}}\right]$} & {$\left[\mathrm{p}^{\mathrm{h}}\right]$} \\
\hline $\begin{array}{l}{\left[\operatorname{tik}^{\mathrm{h}} \mathrm{i},\right.} \\
\left.\operatorname{kak}^{\mathrm{h}} \mathrm{a}\right]\end{array}$ & $\begin{array}{l}\text { [chit }{ }^{{ }^{\mathrm{i}}} \mathrm{i} \\
\text { pat }^{\mathrm{h}} \mathrm{a} \text { ] }\end{array}$ & $\begin{array}{l}\text { [tithi, } \\
\text { gatha] }\end{array}$ & $\begin{array}{l}\text { [p }{ }^{\mathrm{h}} \mathrm{ip}^{\mathrm{h}} \mathrm{i} \\
\text { lapha] }\end{array}$ \\
\hline$[\mathrm{g}]$ & [d] & [d] & [b] \\
\hline [bigi, jaga] & [pidi, pada] & $\begin{array}{l}\text { [didi, } \\
\text { dada] }\end{array}$ & [bibi, baba] \\
\hline$\left[\mathrm{g}^{\mathrm{h}}\right]$ & {$\left[\mathrm{d}^{\mathrm{h}}\right]$} & {$\left[\mathrm{d}^{\mathrm{f}}\right]$} & {$\left[b^{\mathrm{f}}\right]$} \\
\hline $\begin{array}{l}\text { [g }{ }^{\mathrm{f}} \mathrm{gg}^{\mathrm{f}} \mathrm{i}, \\
\operatorname{ag}^{\mathrm{h}} \text { at] }\end{array}$ & $\begin{array}{l}\text { pid }^{\mathrm{f}} \mathrm{i}, \\
\left.\operatorname{gad}^{\mathrm{f}} \mathrm{a}\right]\end{array}$ & $\begin{array}{l}{\left[\mathrm{d}^{\mathrm{f}} \mathrm{id} \mathrm{d}^{\mathrm{f}} \mathrm{i},\right.} \\
\left.\operatorname{ad}^{\mathrm{f}} \mathrm{a}\right]\end{array}$ & {$\left[\mathrm{tib}^{\mathrm{f}} \mathrm{i}, \mathrm{ab}^{\mathrm{f}} \mathrm{ar}\right]$} \\
\hline
\end{tabular}

The utterances were recorded using Sony ECMMS908C Electret Condenser Microphone and EDIROL, R09HR audio recorder maintaining a distance of 10-12 inches between the microphone and the mouth of the speaker in waveform files with $44000 \mathrm{~Hz}$ audio sample rate, 1411 bit rate and 24-bit resolution. 
18 / Aspiration in ...

\subsection{The speakers}

Six fluent native speakers of Nepali, three males and three females, with normal speech capacity were recruited for the experiment. The speakers have been included from different age groups as presented in Table 2.

Table 2: The sample of the speakers

\begin{tabular}{|l|l|l|l|}
\hline S. N. & Age group & Gender & \multicolumn{2}{|l|}{} \\
\hline 1 & $21-30$ & male [DA] & female [JA] \\
\hline 2 & $31-40$ & male [HR] & female [GY] \\
\hline 3 & $41-50$ & male [KR] & female [KL] \\
\hline
\end{tabular}

\subsection{Analysis of the data}

The recorded data were edited using Audacity, an audio editing software and were analyzed using PRAAT a sophisticated and widely used software for acoustic analysis. This study has focused on the effect of aspiration on the plosive itself and the preceding vowel and the following vowel. Oscillogram, spectrum and spectrogram of the sounds were used as the devices for analysis. The techniques of measurement are based on Ladefoged (2003). The statistical calculations were made using http://vassarstats.net/, a statistical calculation website.

This research has followed the segmentation model proposed by Mikuteit and Reetz (2007) for the study of the East Bengali plosive sounds. This model proposes four phases in vowel-plosivevowel sequence as presented in Fig. 1.

Preceding vowel duration (PVD)

It is the duration of the vowel preceding the plosive. Its duration begins with the end of the preceding segment and ends at the beginning of the closure duration of the plosive.

\section{Closure Duration (CD)}

It is the duration of the hold phase of the plosive production. It begins with the end of the preceding vowel and ends at the release of the closure. The end of the preceding vowel is indicated by the sudden cessation of the high amplitude vocal fold vibration of the vowel and beginning of the silence (for voiceless) or very low amplitude buzz (for voiced). Similarly, the end of the closure is indicated by beginning of the release burst indicated by a short spike.

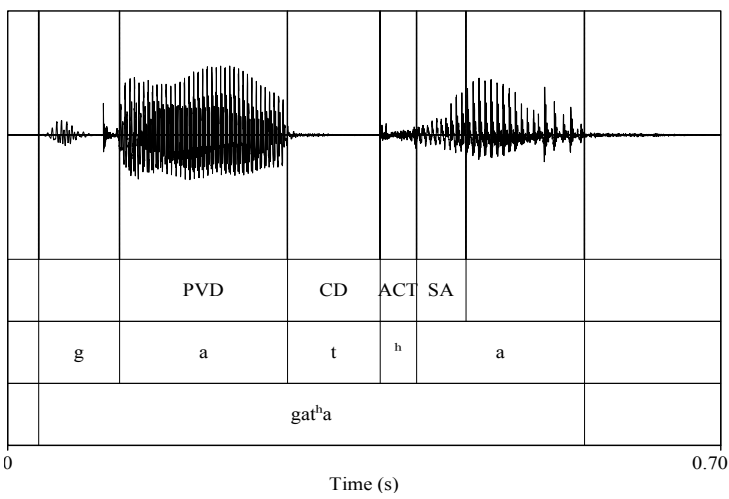

Figure 1: The phases in vowel-plosive-vowel sequence

\section{After Closure Time (ACT)}

This is the duration from the first release burst to the beginning of the first regular glottal pulses of the following vowel. The ACT is characterized by the aperiodic noise component. Itis the term used instead of VOT where VOT is the voicing lag after the burst of a voiceless plosive but ACT is used to refer to such aperiodic noise in both voiceless and voiced plosives.

Superimposed aspiration (SA)

It begins with the end of the after closure time (ACT) and ends at the decrease of end of the friction noise caused by aspiration. It is rather difficult to identify the end of SA because there is no clear demarcation to indicate the end of SA; it is a continuum. It gradually decreases from the beginning to the end of the vowel. Similarly, the nature of SA varies according to the nature of the plosive. It is lighter following an unaspirate and heavier following an aspirate. Similarly, it varies according to the voicing of a plosive as it is lighter following an unaspirated and heavier following an aspirate.The effect of the aspiration can be seen in a spectrogram as the degree of fadedness.

3 The results

3.1 Aspiration and the preceding vowel duration (PVD) 
The average PVD is slightly longer for aspirates $(175 \mathrm{~ms}, \mathrm{SD}$ (standard deviation) $=40)$ and slightly shorter for unaspirates $(172 \mathrm{~ms}, \mathrm{SD}=33)$. But a one-way ANOVA indicates that the PVD does not depend on the aspiration of a plosive $(F(1,15)=$ $0.33, \mathrm{p}=0.5741)$. The result is the same, separately, for both voiced and voiceless plosives. For voiceless aspirates the average PVD is $152 \mathrm{~ms}$ $(\mathrm{SD}=32)$ and for voiceless unaspirates the average $\mathrm{PVD}$ is $150 \mathrm{~ms}(\mathrm{SD}=26)$ where $\mathrm{F}(1,7)=0.06$, $p=0.8135$. Similarly, for voiced aspirates the average PVD is $199 \mathrm{~ms}(\mathrm{SD}=32)$ and for voiced unaspirates the average PVD is $194 \mathrm{~ms}(\mathrm{SD}=25)$ where $F(1,7)=0.26, p=0.6257$. It suggests that PVD is independent of aspiration both in voiceless and voiced plosives. Moreover it suggests that the relation between voiceless unaspirates and voiceless aspirates is parallel to the relation between voiced unaspirates and voiced aspirates regarding the PVD.

\subsection{Aspiration and closure duration (CD)}

Aspiration has significant effect on the $\mathrm{CD}$ of a plosive as aspirates are shorter than the unaspirates in the approximate ratio of 3:4. The average $\mathrm{CD}$ for the aspirates is $63 \mathrm{~ms}(\mathrm{SD}=11)$ and the average $\mathrm{CD}$ for the unaspirates is $80 \mathrm{~ms}$ $(\mathrm{SD}=21)$. A one-way ANOVA indicates that the relationship between aspiration and closure duration is statistically very significant as F (1, $15)=27.52, p<0.0001$

The relationship between aspiration and $\mathrm{CD}$ of the plosives is the same,separately, for both voiced and voiceless ones. For the voiceless aspirates, the $\mathrm{CD}$ is $72 \mathrm{~ms} \quad(\mathrm{SD}=6)$ and for the voiceless unaspirates $\mathrm{CD}$ is $98 \mathrm{~ms}(\mathrm{SD}=13)$ where $\mathrm{F}(1,7)=$ $31.81, \mathrm{p}=0.0007$. Likewise, the $\mathrm{CD}$ for voiced aspirates is $54 \mathrm{~ms} \quad(\mathrm{SD}=8)$ and for voiced unaspirates is $63 \mathrm{~ms}(\mathrm{SD}=6)$ where $F(1,7)=$ 19.3, $\mathrm{p}=0.0031$. So, the facts justify that the relation between voiceless unaspirates and aspirates is parallel to the relation between voiced unaspirates and aspirates regarding the $\mathrm{CD}$.

\subsection{Aspiration and After Closure Time (ACT)}

Aspiration has significant effect on ACT. The ACT of the aspirates is remarkably longer than that of the unaspirates. It is comparatively far longer in the voiceless plosives than in the voiced plosives so the comparison of the average values of the voiced and voiceless plosives will not be logical.

For the voiceless aspirates, the average ACT is 69 $\mathrm{ms}(\mathrm{SD}=20)$ and for the voiceless unaspirates, it is $20 \mathrm{~ms}(\mathrm{SD}=9)$ where $\mathrm{F}(1,7)=99.37, \mathrm{p}<0.0001$. Similarly, for the voiced aspirates, the average $\mathrm{ACT}$ is $7 \mathrm{~ms}(\mathrm{SD}=3.7)$ and for the voiced unaspirates it is $4 \mathrm{~ms}(\mathrm{SD}=1.7)$ where $\mathrm{F}(1,7)=$ $3.88, p=0.0895$ (which is slightly less than the required confidence level). The burst and frication period of the voiced plosives is very weak in Nepali and the voiced aspirates are produced fricatives in most of the situations. So measuring ACT in the Nepali plosives is indeed challenging. Still the relation between the voiceless aspirates and voiceless unaspirates; and voiced aspirates and voiced unaspirates have the same and parallel pattern.

\subsection{Aspiration and Superimposed Aspiration (SA)}

Aspiration has substantial effect on the SA of a plosive. It is longer in the aspirates and shorter in the corresponding unaspirates in the approximate ration of $2: 1$. The average value for the voiced aspirates is $53 \mathrm{~ms} \quad(\mathrm{SD}=7)$ and for voiced unaspirates is $24 \mathrm{~ms}(\mathrm{SD}=8)$ where $\mathrm{F}(1,7)=$ $133.83, \mathrm{p}<0.0001$. Similarly, the average value for the voiceless aspirates is $28 \mathrm{~ms}(\mathrm{SD}=6)$ and for voiced unaspirates is $16 \mathrm{~ms}(\mathrm{SD}=6)$ where $\mathrm{F}(1,7)$ $=16.05, \mathrm{p}<0.0051$.

It indicates that aspiration has remarkable effect on the SA of a plosive in both voiceless and voiced plosives. Moreover it suggests that the relation between voiced aspirates and voiced unaspirates and voiceless aspirates and voiceless unaspirates is parallel regarding their SA values.

\section{Discussion and conclusions}

This experiment shows that the characters that voiceless unaspirated plosivesdepict are completely shared by the voiceless aspirated plosives and all the features depicted by the voiced unaspirated plosives are shared by the voiced aspirated plosives, too. So the voiced aspirated plosives make a common class with their unaspirated counterparts. Similarly, the patterns of acoustic relations between the voiceless unaspirated plosives and the voiceless 
aspirated plosives are parallel to the patterns of acoustic relations between the voiced unaspirated plosives and the voiced aspirated plosives. The relation can be presented symbolically as:

voiceless unaspirated plosive : voiceless aspirated plosive $=$ voiced unaspirated plosive : voiced aspirated plosive

The parallel phonetic features between the voiceless aspirated plosives and the voiced aspirated plosives with reference to their unaspirated counterparts justifies that voiced aspirated plosives are aspirates in reality but not a distinct mode of phonation as mentioned in the literature. So it is not logical to regard the voiced aspirates as a distinct mode of phonation and term them as 'breathy voiced' but they are the combination of voicing and aspiration.

The term 'breathy voiced' is misleading because the term 'breathy' is used to refer to the breathy sonorants and vowels which are voiced. So the breathy sonorants and vowels are breathy voiced in reality. The next point to remember is that breathiness is a hold period feature of the sounds but the term 'breathy voiced' has been used based on the after release feature of the plosive and more over based on the effect of the plosive on the following vowel, in fact, which is not the part of the plosive. In reality, the breathiness in the following vowel is found in the case of voiceless aspirates, voiceless unaspirates and voiced unaspirates, too.

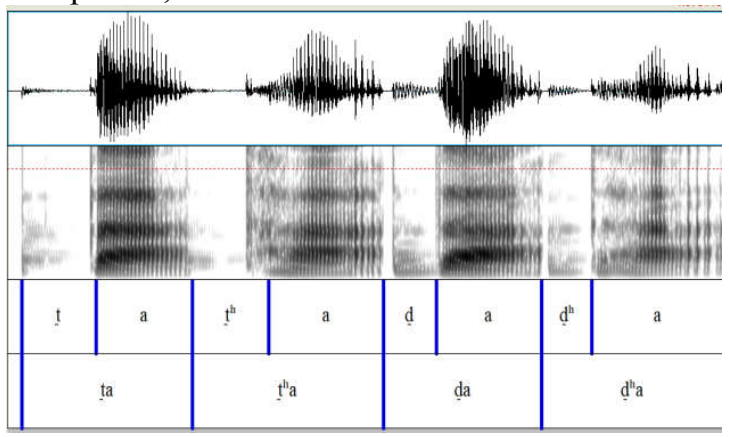

Figure 2: The breathiness in the vowel after [t], $\left[\mathrm{t}^{\mathrm{h}}\right],[\mathrm{d}]$ and $\left[\mathrm{d}^{\mathrm{h}}\right]$ compared

It is a matter of degree, as in Figure 2, which can be presented in order as: voiceless unaspirate $<$ voiced aspirate < voiceless aspirate < voiced aspirate.

So aspiration needs to be defined to accommodate the voiceless aspirates and voiced aspirates as well. If we define aspiration as the release feature of a plosive as an extra air released with glottal and supraglottal friction causing noise, we can handle the aspiration in the four-category languages like Nepali, Hindi, etc. The release of a plosive includes transient (burst), frication (the opening period which is similar to the fricative production), and optionally aspiration (noise as a result of friction at the glottis and supraglottal region).

It would maintain the parallel terms between phonetics and phonology and we should not bear the expense of another new term.

\section{References}

Benguerel, Andre P. \& Bhatia, Tej K. 1980. Hindi stop consonants: An acoustic and fiber-scopic study. Phonetica, 37, 134-148.

Chalise, Krishna P. 2017. Acoustic analysis of the plosives in Nepali. Gipan, 3.1: 41-64: Central Department of Linguistics, T. U., Kathmandu.

Dixit, R. P. 1989.Glottal gestures in Hindi plosives.Journal of Phonetics, 17.3, 213-237.

Dutta, Indranil. 2007. Four-way contrast in Hindi: an acoustic study of voicing, fundamental frequency and spectral tilt. A dissertion submitted in partial fulfillment of the requirements for the degree of doctor of philosophy in linguistics in the Graduate College of the University of Illinois. UrbanaChampaign.

Harrington, Jonathan. 2010. Acoustic Phonetics. In The Handbook of Phonetic Sciences. William J. Hardcastle, John Laver and Gibbon Fiona (Eds.), 81-129. Chichester: Wiley-Blackwell. Ingemann, Frances and Yadav, Ramawatar. 1978. Voiced aspirated consonants.Papers from the 1977 Mid-America Linguistics Conference. Columbia.University of Missouri, pp. 337-344.

Johnson, Keith. 1997. Acoustic and Auditory Phonetics. Cambridge and Oxford: Blackwell Publishers. 
Kagaya, R. and Hirose, H. 1975. Fiberoptic, electromyographic and acoustic analyses of Hindi stop consonants. Annual Bulletin of the Research Institute of Logopedics and Phoniatrics (Tokyo). 9, 27-46.

Ladefoged, Peter and Keith Johnson. 2011. A Course in Phonetics. 6th Boston: Wadsworth Cenage Learning.

Ladefoged, Peter. 1975. A course in phonetics. New York: Harcourt Brace Jovanovich.

Ladefoged, Peter. 2003. Phonetic data analysis: An introduction to fieldwork and instrumental techniques. Oxford: Blackwell publishers.

Laver, John. 1994. Principles of phonetics: Cambridge University Press.

Lisker, L. and Abramson, A. S. 1964. A crosslanguage study of voicing in initial stops: acoustical measurements. Word, 20, 384-422.

Lombardi, Linda. 1994, Laryngeal features and laryngeal neutralization(Outstanding dissertations in Linguistics). Garland Publishing.

Mikuteit, Simon. \& Reetz, Henning. 2007. Caught in the ACT: The timing of aspiration and voicing in East Bengali. Language \& Speech, 50.2, 249-279.

Ohala, Manjari and Ohala, John. 1972. The problem of aspiration in Hindi phonetics. In Annual Bulletein of Research Institute of Logopedics and Phoniatrics, Faculty of Medicine, University of Tokyo, 6, 39-46.

Pokharel, Madhav.P. 1989. Experimental analysis of Nepali sound system. Ph.D. Dissertation. Deccan College, Pune.

Poon, Pamela G. and Mateer, Catherine A. 1985, A study of VOT in Nepali stop consonants, Phonetica42, 39-47.

Reetz, Henning, \& Jongman, Allard. 2009. Phonetics: Transcription, production, acoustics, and perception. West Sussex, UK: WileyBlackwell.

Vicenik, Chad. 2008. Acoustic study of Georgian stop. Working Papers in phonetics, Paper1_No107 in Department of Linguistics, UCLA.

Watters, Stephen A. 2002. The sounds and tones of five Tibetan languages of the Himalayan region. Linguistics of the Tibeto-Burman Area, 22.1, 1-65.
Yadav, Ramawatar. 1984. Voicing and aspiration in Maithili: a fiberoptic and acoustic study. Indian Linguistics. 45, 1-25.

Acknowledgements

This paper is based on the research report entitled 'Acoustic Analysis of the Nepali Plosives' submitted to the University Grants Commission (UGC), Nepal in 2016 as the research report of Mini Research Grant which was awarded to me in 2015. I would like to thank the University Grants Commission, Nepal for the encouragement. 